\title{
Maternal smoking and congenital malformations: an epidemiological study
}

\author{
JENNIFER L. KELSEY, TERENCE DWYER, THEODORE \\ R. HOLFORD, AND MICHAEL B. BRACKEN
}

From the Department of Epidemiology and Public Health, Yale University School of Medicine, Connecticut, USA

SUMMARY In a case-control study undertaken in several hospitals in Connecticut, it was found that women who reported smoking more than 20 cigarettes a day during pregnancy had a relative $\vec{\omega}$ risk of about 1.6 for congenital malformations in the offspring of that pregnancy compared with $\frac{\rho}{\infty}$ women who said they had not smoked at all during pregnancy. However, there was no significant $\stackrel{\odot}{\rightarrow}$ increase in risk among women who reported smoking 20 or fewer cigarettes a day during pregnancy $\dot{N}_{N}$ compared with those who said they had not smoked at all during pregnancy. The higher risk $i$ among moderate and heavy smokers could not be attributed to any of the potentially confounding $\vec{\sim}$ variables considered in this study; furthermore, it was specific to smoking during pregnancy rather than before pregnancy, and increased with the average amount smoked a day. Nevertheless, because the increase in risk was modest, because response bias could exist in a study of this type, and because $\bar{c}$ no other studies have examined in detail the smoking-congenital malformation hypothesis, furth $\overbrace{}^{\circ}$ research is needed to determine whether the relationship between maternal smoking and congenita malformations in offspring is causal.

\section{Introduction}

An association between maternal smoking and low infant birth weight has been observed in many epidemiological studies, but much less attention has been focused on the possibility of a relationship between maternal smoking and congenital malformations in offspring. The few studies of this hypothesis have indicated that if there is an association between maternal smoking and congenital malformations, it is probably only a small one (Lowe, 1959; Mulcahy and Knaggs, 1968; Andrews and McGarry, 1972). Estimates of relative risk calculated from published studies have generally ranged from 1.1 to 1.5 for the relationship between smoking in any amount and all malformations (Lowe, 1959; Mulcahy and Knaggs, 1968; Andrews and McGarry, 1972), and one study (Underwood et al., 1965) suggested no increase in risk at all. However, with one exception (Andrews and McGarry, 1972), the numbers of cases have been small, and in no single study was statistical significance reached. In one of the studies (Andrews and McGarry, 1972), particularly strong associations were found between maternal smoking and cleft palate and lip, gastrointestinal abnormalities, and neural tube defects. An association of heavy smoking $\Phi$ with neural tube defects was also reported in an investigation specifically devoted to the epidemiology of that disorder (Choi and Klaponski, 1970).

Thus, further investigation is needed into the possibility of an association between smoking and congenital malformations. To determine whether an apparently slightly increased risk is real or ? spurious is a difficult exercise, so it is important to examine specific characteristics of the association, such as whether there is a dose-response relationship, whether any confounding variables can alter the relationship, and whether the association is specific to smoking during rather than before pregnancy.

During a case-control study of the relationship between oral contraceptives and congenital mal- $N$ formations in Connecticut, detailed information was collected on the smoking habits of the respon- 0 dents. This provided an opportunity to examine $\omega$ further the relationship between smoking in pregnant women and congenital malformations in their $\stackrel{0}{\circ}$ offspring. 


\section{Methods}

Mothers of infants with congenital malformations were identified from two sources. About $90 \%$ of the infants were diagnosed as having congenital malformations within one year of their date of birth in five large general hospitals in Connecticut during the period 1974 to 1976 ; about $10 \%$ were in private clinics in Connecticut during the same period. Since there were no systematic differences in the characteristics of the mothers of infants coming from the two sources, they are combined in the analysis. The diagnosis of the referring institution was generally the basis for defining a case, but all medical data collected were reviewed by a paediatrician or internist associated with the study, and further information was requested when necessary.

The controls were selected by taking a random sample of mothers who gave birth to normal infants in the five hospitals on two or three days a week, the exact number of days depending on the number of deliveries in the hospital. The sampling days were rotated so that all days of the week were equally represented during a seven-week period. The ratio of all controls to all cases was $2 \cdot 3$ to 1 . Like the mothers of cases, mothers of controls had to be interviewed within one year of the birth to be included in the study.

Most information on possible risk factors was obtained by means of a standardised questionnaire given by trained interviewers to mothers of all cases and controls. The questionnaire covered demographic characteristics, height and weight, pregnancy history, contraceptive history, use of certain drugs, source of water supply, exposure to $x$ rays during pregnancy, diabetes, hypertension, rubella, and cigarette smoking. Verification of the details of medication history was requested as a matter of routine from the subjects' physicians.

Although $86 \%$ of mothers of controls were interviewed in the hospital immediately after giving birth, only $19 \%$ of mothers of cases were interviewed in the hospital. The two main reasons for this difference were that (a) in many instances the diagnosis was not made until some time after birth and (b) the woman's physician frequently wanted to allow her time to recover from the emotional stress of giving birth to an infant with an abnormality before she was interviewed. All women not interviewed in hospital were interviewed at home.

The participation rate for mothers of cases was $71 \%$, and for mothers of controls, $90 \%$. The lower rate among mothers of cases was mainly attributable to the failure of the physicians to give permission for the interview, and the inability of the interviewers to reach the women within the specified time limit of one year after birth.
To simplify the interpretation of results, the 56 mothers of twins and triplets have been omitted from the analysis. Also excluded are 15 women whose responses were judged unreliable by the interviewer. Responses from the first interview only are included for the 17 women who entered the study population twice because they had two completed pregnancies during the period of the investigation.

\section{Results}

The study population was composed of 1370 cases and 2968 controls. Their distribution by maternal age and race is shown in Table 1. Most mothers were white and aged 20 to 29 .

Forty-one per cent of the mothers of cases and $39 \%$ of the mothers of controls reported having smoked at some time during pregnancy, a difference which is not statistically significant. The estimate of relative risk was $1 \cdot 10$, with $95 \%$ confidence limits ranging from 0.97 to $1 \cdot 26$.

Table 1 Distribution of cases and controls according to maternal age and race*

\begin{tabular}{|c|c|c|c|c|}
\hline \multirow{3}{*}{$\begin{array}{l}\text { Maternal } \\
\text { age }\end{array}$} & \multicolumn{3}{|l|}{ Cases } & \multirow[b]{3}{*}{ Total } \\
\hline & \multicolumn{3}{|l|}{ Race } & \\
\hline & White & Black & Other & \\
\hline \multirow[t]{3}{*}{$\begin{array}{l}<20 \\
20-24 \\
25-29 \\
30-34 \\
35-39 \\
\geqslant 40 \\
\text { Total }\end{array}$} & $\begin{array}{r}73 \\
292 \\
464 \\
252 \\
61 \\
17 \\
1159\end{array}$ & $\begin{array}{r}55 \\
56 \\
39 \\
14 \\
6 \\
1 \\
171\end{array}$ & $\begin{array}{r}9 \\
12 \\
10 \\
5 \\
1 \\
0 \\
37\end{array}$ & $\begin{array}{r}137 \\
360 \\
513 \\
271 \\
68 \\
18 \\
1367\end{array}$ \\
\hline & \multicolumn{3}{|c|}{ Controls } & \multirow[b]{3}{*}{ Total } \\
\hline & \multicolumn{3}{|c|}{ Race } & \\
\hline $\begin{array}{l}\text { Maternal } \\
\text { age }\end{array}$ & White & Black & Other & \\
\hline $\begin{array}{l}<20 \\
20-24 \\
25-29 \\
30-34 \\
35-39 \\
\geqslant 40 \\
\text { Total }\end{array}$ & $\begin{array}{r}213 \\
627 \\
1101 \\
466 \\
101 \\
17 \\
2525\end{array}$ & $\begin{array}{r}112 \\
126 \\
90 \\
38 \\
8 \\
1 \\
376\end{array}$ & $\begin{array}{r}12 \\
21 \\
17 \\
9 \\
3 \\
0 \\
62\end{array}$ & $\begin{array}{r}337 \\
774 \\
1208 \\
513 \\
112 \\
18 \\
2963\end{array}$ \\
\hline
\end{tabular}

* Race or age was unknown for 3 cases and 5 controls

Table 2 Distribution of mothers of cases and controls according to average number of cigarettes smoked a day during the third month of pregnancy and estimated relative risks for congenital malformations in offspring according to amount smoked a day*

\begin{tabular}{|c|c|c|c|c|c|}
\hline \multirow{2}{*}{$\begin{array}{l}\text { No. } \\
\text { cigarettes } \\
\text { smoked a } \\
\text { day }\end{array}$} & \multicolumn{2}{|c|}{ Mothers of cases } & \multicolumn{2}{|c|}{ Mothers of controls } & \multirow{2}{*}{$\begin{array}{l}\text { Relative } \\
\text { risk } \\
\text { estimate }\end{array}$} \\
\hline & No. & $\%$ & No. & $\%$ & \\
\hline $\begin{array}{l}0 \\
1-10 \\
11-20 \\
21-30 \\
\geqslant 31 \\
\text { Total }\end{array}$ & $\begin{array}{r}889 \\
182 \\
203 \\
55 \\
40 \\
1369\end{array}$ & $\begin{array}{r}64 \cdot 9 \\
13 \cdot 3 \\
14.8 \\
4.0 \\
2.9\end{array}$ & $\begin{array}{r}1988 \\
426 \\
420 \\
86 \\
48 \\
2968\end{array}$ & $\begin{array}{r}67.0 \\
14.4 \\
14.2 \\
2.9 \\
1.6\end{array}$ & $\begin{array}{l}1.0 \\
1.0 \\
1.1 \\
1.4 \\
1.9\end{array}$ \\
\hline
\end{tabular}

* Number of cigarettes smoked a day during the third month of pregnancy was unknown for the mother of one case 
Table 3 Estimate of relative risk * for congenital malformations by diagnostic category, according to number of cigarettes smoked a day during third month of pregnancy

\begin{tabular}{|c|c|c|c|c|}
\hline \multirow[b]{2}{*}{ Diagnostic categoryt } & \multirow[b]{2}{*}{ (ICD numbers) } & \multirow[b]{2}{*}{ Number of cases } & \multicolumn{2}{|c|}{ Relative risk estimates* } \\
\hline & & & $\begin{array}{l}1-20 \text { cigarettes } \\
a \text { day }\end{array}$ & $\begin{array}{l}21 \text { or more cigarettes } \\
\text { a day }\end{array}$ \\
\hline \multirow{4}{*}{$\begin{array}{l}\text { Hemangioma, lymphangioma } \\
\text { Inguinal hernia } \\
\text { Anencephaly, spina bifida, } \\
\text { hydrocepholus } \\
\text { Common truncus, transposition of } \\
\text { the great vessels, tetralogy of Fallot } \\
\text { Septal defects } \\
\text { Abnormalities of heart valves } \\
\text { Other abnormalities of circulatory } \\
\text { system } \\
\text { Cleft palate and cleft lip } \\
\text { Pyloric stenosis } \\
\text { Abnormalities of digestive system } \\
\text { Club foot } \\
\text { Poly-syndactyly } \\
\text { Other musculoskeletal disorders } \\
\text { Abnormalities of skin } \\
\text { Down's syndrome and abnormalities } \\
\text { of sex chromosome }\end{array}$} & $\begin{array}{l}(227.0-227.2) \\
(550.0-552.0) \\
(740.0-743.3)\end{array}$ & $\begin{array}{r}51 \\
106 \\
82\end{array}$ & $\begin{array}{l}1 \cdot 0 \\
1 \cdot 3 \\
1 \cdot 3\end{array}$ & $\begin{array}{l}1 \cdot 8 \\
2 \cdot 8 \\
1 \cdot 8\end{array}$ \\
\hline & $(746.0-746.2)$ & 54 & $1 \cdot 3$ & $0 \cdot 4$ \\
\hline & $\begin{array}{l}(746.3-746.4) \\
(746.6) \\
(746.7-747.6)\end{array}$ & $\begin{array}{r}213 \\
52 \\
106\end{array}$ & $\begin{array}{l}1 \cdot 0 \\
1 \cdot 5 \\
0 \cdot 9\end{array}$ & $\begin{array}{l}1 \cdot 4 \\
2 \cdot 0 \\
1 \cdot 0\end{array}$ \\
\hline & $\begin{array}{l}(749.0-749.2) \\
(750.1) \\
(750.2-751.8) \\
(754.0-754.9) \\
(755.0-755.1) \\
(755.2-756.8) \\
(757.1-757.9) \\
(759.3-759.5)\end{array}$ & $\begin{array}{l}40 \\
71 \\
56 \\
73 \\
50 \\
91 \\
46 \\
52\end{array}$ & $\begin{array}{l}1 \cdot 0 \\
1 \cdot 3 \\
1 \cdot 4 \\
1 \cdot 2 \\
0 \cdot 6 \\
0 \cdot 8 \\
0 \cdot 8 \\
1 \cdot 1\end{array}$ & $\begin{array}{l}1 \cdot 7 \\
3 \cdot 3 \\
2 \cdot 9 \\
1 \cdot 3 \\
1 \cdot 6 \\
1 \cdot 1 \\
1 \cdot 9 \\
1 \cdot 8\end{array}$ \\
\hline
\end{tabular}

The mothers of cases and controls were next compared according to the number of cigarettes smoked a day during the third month of pregnancy. This month was chosen arbitrarily. Since there was very little change in smoking habits during pregnancy, the data for each of the months indicate similar trends. Table 2 gives the percentages of mothers of cases and controls according to the number of cigarettes they reported smoking a day, and the Figure shows the corresponding estimates of relative risk for the various smoking levels. It can be seen that there was a steady increase in the relative risk with the increase in the number of cigarettes smoked a day. $\left(\triangle \mathrm{G}^{2}=10 \cdot 13, \mathrm{df}=2\right.$, $\mathbf{P}<\cdot 001$ for test of linear trend).* There was a slight increase up to one pack a day, but for more than that there was a more marked increase. Since most women reported that they smoked one pack a day or less, the overall association between congenital malformations and smoking appears slight.

Table 3 gives estimates of relative risk for women who smoked 1-20 cigarettes a day, and for those who smoked more than 20 cigarettes a day, for the major diagnostic groups in the study. In calculating these estimates, mothers of cases in each diagnostic group have been compared with mothers of controls, eliminating mothers of all other cases when making an estimate for an individual diagnostic group. It can be seen that there was very little increase in risk for any malformation among mothers who smoked 1-20 cigarettes a day, whereas with only a few exceptions

*G2 is the likelihood ratio $\chi^{2}$ goodness-of-fit test. $G^{2}=2 \Sigma 0$ in $(O / E)$, where $O=$ observed frequency and $E=$ expected frequency based on the log-linear model. The test of statistical significance for a particular set of parameters is given by the change in the likelihood ratio $\chi^{2}$ test when a set of parameters is dropped; this change is denoted by $\Delta G^{2}$. (Bishop et al., 1975). (truncoconal abnormalities, other abnormalities of the circulatory system, and other musculoskeletal in disorders), the risk was substantially increased among $\overrightarrow{-}$ mothers who smoked more than one pack a day. $N$ Although the relative risk estimates were highest for 을 pyloric stenosis, abnormalities of the digestive $\overrightarrow{ }$ system, and inguinal hernia, the data suggest tha the elevation in risk is general, rather than being specific for certain malformations

The possibility was considered that the association of congenital malformations with smoking more than one pack a day could be attributed to confounding variables. In these data, six possibly confounding variables were identified: maternal age, social class (indicated by the occupation of the head

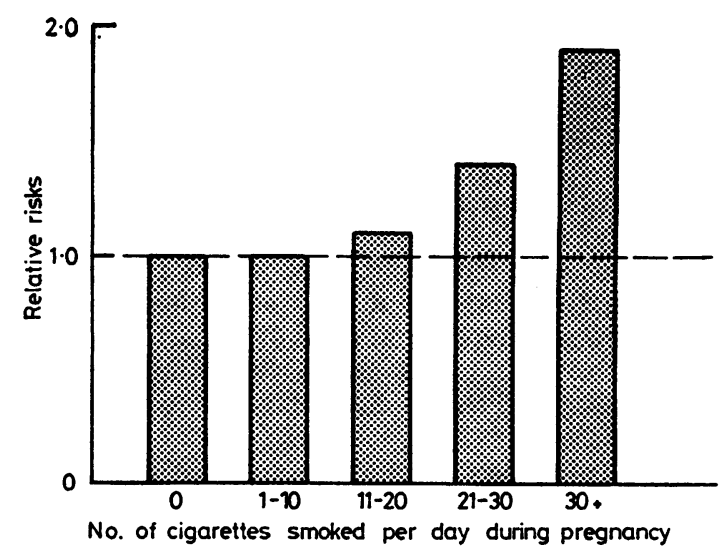

Figure Estimated relative risks for congenital malfor- N mations in offspring according to the average number of 0 cigarettes smoked a day by mothers during the third month of pregnancy 
of the household), marital status, religion, parity, and race. All six were associated at least to a certain extent either positively or negatively with both smoking and congenital malformations. Each of these potentially confounding variables was controlled, first individually and then in combination, using the Mantel-Haenszel procedure (Mantel and Haenszel, 1959). The estimates of relative risk among those who smoked 1-20 cigarettes a day and among those who smoked 21 or more cigarettes a day remained 1.0 and 1.6 respectively, when all variables were taken into account. Similar estimates of relative risk $(1 \cdot 0$ and 1.5 respectively) were obtained when a loglinear model (Bishop et al., 1975) was fitted to the data to control for confounding variables. The loglinear model analysis also indicated that the association between smoking and congenital malformations was consistent for the various subgroups into which the study population could be divided.

Next, an attempt was made to differentiate the effect of smoking during pregnancy from any effect of smoking before pregnancy, again using the third month before conception and the third month after conception as indicators of the average number of cigarettes smoked before and during pregnancy respectively. Table 4 shows that relative risk estimates were 1.6 for women who had smoked more than 20 cigarettes a day during pregnancy, and 1.0 for women who had smoked 1-20 cigarettes a day during pregnancy, when adjustment was made for the association of smoking before pregnancy with smoking during pregnancy, and for the association of smoking before pregnancy with congenital malformations. The adjusted relative risk estimates for smoking before pregnancy were 1.0 for smokers of more than 20 cigarettes a day and 1.1 for smokers of 1-20 cigarettes a day, indicating no association between smoking before pregnancy and congenital malformation in offspring when the associations of these two variables with smoking during pregnancy are taken into account.

Finally, the respondents were also asked whether they had been exposed to someone else's cigarette smoke on most days for at least two hours a day during their pregnancies. When a log-linear model was fitted to adjust for the number of cigarettes they themselves had smoked during pregnancy, exposure to the smoke of others was associated with a relative risk of only $1 \cdot 1\left(\Delta \mathbf{G}^{2}=1 \cdot 25, \mathrm{df}=1\right.$, $P=0.26$ ).

\section{Discussion}

In this study, detailed information was sought about smoking habits during and before pregnancy from relatively large numbers of mothers of infants with congenital malformations and from mothers of apparently healthy infants, yet conclusive results have not been obtained. The data accord with a causal role for moderate and heavy smoking, but the lack of an increase in risk among light smokers, who constitute the majority of pregnant women who smoke, is puzzling. Before discussing this further, however, two possible sources of bias should be examined.

The first is response bias, or the possibility that the cases and controls under-stated or over-stated their smoking habits to different extents. The greater amount of time that elapsed between the interviews of case mothers and the births of their children compared with the time that elapsed between the interviews of control mothers and the births of their children could have added to this possible bias. It is obviously impossible to say whether such bias had an effect on the results of this study, and also to predict whether it would have increased or decreased any association between smoking and congenital malformations. However, it is unlikely that response bias would account for the dose-

Table 4 Relationships among average number of cigarettes smoked a day during third month of pregnancy, average number of cigarettes smoked during third month before pregnancy, and presence or absence of congenital malformations in offspring

\begin{tabular}{|c|c|c|c|c|c|}
\hline \multirow[b]{2}{*}{ Variables } & \multicolumn{2}{|c|}{$\begin{array}{l}\text { Adjusted estimate of relative risk* for } \\
\text { congenital malformations }\end{array}$} & \multicolumn{3}{|c|}{$\begin{array}{l}\text { Test of significance of relationship controlling for associations } \\
\text { with other variables* }\end{array}$} \\
\hline & $\begin{array}{l}\text { Smokers of } \leqslant 20 \\
\text { cigarettes a day }\end{array}$ & $\begin{array}{l}\text { Smokers of } \geqslant 21 \\
\text { cigarettes a day }\end{array}$ & $D F$ & $\Delta G^{2}$ & $\boldsymbol{P}$ \\
\hline $\begin{array}{l}\text { No. cigarettes smoked a day during } \\
\text { pregnancy and congenital } \\
\text { malformations }\end{array}$ & $1 \cdot 0$ & $1 \cdot 6$ & 2 & $7 \cdot 08$ & .03 \\
\hline $\begin{array}{l}\text { No. cigarettes smoked a day before } \\
\text { pregnancy and congenital } \\
\text { malformations }\end{array}$ & $1 \cdot 1$ & $1 \cdot 0$ & 2 & $0 \cdot 37$ & $\cdot 83$ \\
\hline $\begin{array}{l}\text { No. cigarettes smoked a day during } \\
\text { pregnancy and no. cigarettes } \\
\text { smoked before pregnancy }\end{array}$ & & & 4 & $3786 \cdot 6$ & $<\cdot 001$ \\
\hline
\end{tabular}


response relationship and for the association with smoking during but not before pregnancy. However, only a cohort study could definitively rule this out.

A second possible problem in interpreting these findings is that both smoking and congenital malformations are associated with some third factor which is distorting the true association. Maternal age, parity, social class, and alcohol consumption are variables that need to be considered (Royal College of Physicians of London, 1971; Sucheston and Cannon, 1973). The first three of these variables were in fact taken into account in the analysis and found not to affect the results. Data were not collected on alcohol consumption, and it is known that the amount smoked and the amount of alcohol consumed are correlated (Royal College of Physicians of London, 1971). Although it is unlikely that the association between alcohol consumption and smoking could explain the finding that congenital malformations are associated with smoking during but not before pregnancy, the amount of alcohol consumed remains a conceivable confounding variable which should be examined in future studies. It should also be mentioned that the effect of fetal wastage on the association between smoking and congenital malformations obviously cannot be examined in a study of this type.

In addition to these methodological problems, consideration also needs to be given to the biological plausibility of an association between maternal smoking and congenital malformations in offspring. There is evidence that nicotine crosses the placental barrier and increases the fetal heart rate (Larson et al., 1961); that smoking by pregnant women substantially raises the carboxyhaemoglobin level of the blood of the fetus (Cole et al., 1972); that in animals a high induced concentration of carboxyhaemoglobin in pregnant females is associated with an increased frequency of congenital malformations in offspring (Astrup et al., 1972); and that $\mathrm{N}$-nitroso compounds in cigarette smoke are teratogenic in rats when administered via the respiratory route (Magee et al., 1976). An increase in risk for congenital malformations from cigarette smoking would therefore appear to be biologically plausible, although exactly which mechanisms are involved would have to be worked out.

Finally, the consistency with other epidemiological studies should be examined. The estimate of the relative risk in this study, $1 \cdot 1$, is a little lower than the average of the estimates made from the three previously published studies showing positive results (Lowe, 1959; Mulcahy and Knaggs, 1968; Andrews and McGarry, 1972), but it is in the same range. None of the published studies looked specifically at women who changed their smoking habits. In only one (Mulcahy and Knaggs, 1968) was a doseresponse relationship sought, and it was not found. However, Choi and Klaponski (1970) noted a probable association between 'heavy' smoking and neural tube defects, a finding consistent with the present study. Previously reported associations (Andrews and McGarry, 1972) between smoking and cleft lip and palate, gastrointestinal abnormalities, and neural tube defects accord with the association between moderate and heavy smoking and these disorders found in the present study. Particularly high relative risks were also associated with pyloric stenosis and inguinal hernia in the Connecticut study.

Thus an increase in the risk of giving birth to offspring with congenital abnormalities among women who smoke more than one pack of cigarettes a day during pregnancy remains plausible, but by no means certain. On the one hand, four studies have shown a slightly increased risk among smokers, the association can be explained biologically, and our results suggest that a dose-response relationship exists, that the relationship is specific to smoking during rather than prior to pregnancy, and that several potentially confounding variables do not explain the association. On the other hand the evidence is weak in other respects. The associas tions reported have not been strong ones, mos investigators have not looked for a dose-respons relationship, most have not examined the specificity of the association with smoking during pregnancy, and none has taken alcohol consumption into account. Furthermore, cohort studies are needed to eliminate the problem of response bias, and the question of whether an increase in risk applies to many abnormalities or only to specific ones should be examined. Additional animal experiments would help to clarify a specific mechanism for an association.

Finally, it is interesting to note that if the data on smoking habits of the control mothers in our study provide an accurate representation of the smoking habits of pregnant women in the general population (5\% smoke more than 20 cigarettes a day, one-third smoke cigarettes in any amount), then the population attributable risk per cent is estimated to be $3 \%$ if it is assumed either that (a) the relative risk among all smokers is $1 \cdot 1$ or (b) the relative risk among smokers of more than 20 cigarettes a day is 1.6 but there is no elevation in risk among those who smoke less than that amount. Relative risks of $1 \cdot 2$ and $1 \cdot 3$ among all smokers would lead to estimates of population attributable risk of $6 \%$ and $9 \%$ respectively. So if smoking of cigarettes during $q$ pregnancy is causally related to congenital mal- 0 formations in offspring, it is likely to account for 
only a modest proportion of all malformations. Nevertheless, determining whether this causal relationship exists will be important, because it would shed some light on mechanisms by which congenital malformations occur, and because smoking during pregnancy is, at least theoretically, preventable.

This study was supported by contract N01-HD-52600 from the National Institute of Child Health and Human Development. During part of the period of study, Dr. Kelsey was supported by Career Development Award No. 1-K04-NS-70502 from the National Institute of Neurological and Communicative Disorders and Stroke.

Reprints from Dr. Jennifer L. Kelsey, Department of Epidemiology and Public Health, Yale University School of Medicine, New Haven, Connecticut, USA 06510.

\section{References}

Andrews, J., and McGarry, J. M. (1972). A community study of smoking in pregnancy. Journal of Obstetrics and Gynaecology of the British Commonwealth, 79, 1057-1073.

Astrup, P., Olsen, H. M., Trolle, D., and Kjeldsen, K. (1972). Effect of moderate carbon monoxide exposure on fetal development. Lancet, 2, 1220-1222.

Bishop, Y. M., Fienberg. S. E., and Holland, P. W. (1975). Discrete Multivariate Analysis. MIT Press: Cambridge, Massachusetts.
Choi, M., and Klaponski, S. (1970). On neural tube defects: an epidemiological elicitation of etiological factors (Abstract). Neurology, 20, 399-400.

Cole, P. V., Hawkins, L. H., and Roberts, D. (1972). Smoking during pregnancy and its effects on the fetus. Journal of Obstetrics and Gynaecology of the British Commonwealth, 79, 782-787.

Larson, P. S., Haag, H. B., and Silvette, H. (1961). Tobacco, Experimental and Chemical Studies, p. 390. Williams and Williams: Baltimore.

Lowe, C. R. (1959). Effect of mothers' smoking habits on birth weight of their children. British Medical Journal, 2, 673-676.

Magee, P. N., Montesano, R., and Preussman, R. (1976). N-Nitroso compounds and related carcinogens. In ACS Monograph Series No. 173, Chemical Carcinogens. Edited by C. E. Searle. American Chemical Society: Washington.

Mantel, N., and Haenszel, W. (1959). Statistical aspects of the analysis of data from retrospective studies of disease. Journal of the National Cancer Institute, 22, 719-748.

Mulcahy, R., and Knaggs, J. F. (1968). Effect of age, parity, and cigarette smoking on outcome of pregnancy. American Journal of Obstetrics and Gynecology, 101, 844-849.

Royal College of Physicians of London (1971). Smoking and Health Now, pp. 111-112. Pitman: London.

Sucheston, M. E., and Cannon, M. S. (1973). Congenital Malformations. Case Studies in Developmental Anatomy, p. 8. Davis: Philadelphia.

Underwood, P., Hester, L. L., Laffitle, T., and Gregg, K. V. (1965). The relationship of smoking to the outcome of pregnancy. American Journal of Obstetrics and Gynecology, 91, 270-276 